\title{
Germinação de sementes de Enterolobium schomburgkii (Benth.) Benth. submetidas a estresse salino e aplicação de poliamina
}

BRAGA, L.F.; SOUSA, M.P.; ALMEIDA, T.A.

Universidade do Estado de Mato Grosso - UNEMAT, Caixa Postal 324, CEP 78.580-000, Alta Floresta - MT; *luciabraga@unemat.br; marcilio.sousa@ pq.cnpq.br.

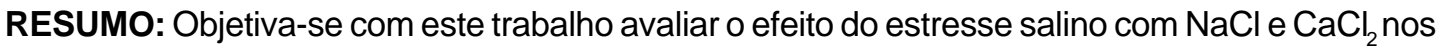
potenciais osmóticos 0 (controle); -0,2; -0,3 e -0,4 MPa com e sem aplicação da poliamina putrescina nas concentrações de $5 \mathrm{mM}$ e $10 \mathrm{mM}$. As sementes de E. schomburgkii foram previamente escarificadas com lixa, no lado oposto à radícula, tratadas com fungicidas e colocadas para germinar nos diferentes tratamentos, à temperatura de $30^{\circ} \mathrm{C}$, sendo utilizadas quatro repetições de 25 sementes. Foi utilizado o delineamento inteiramente casualizado, em esquema fatorial $2 x$ 4 (agentes salinos $x$ potenciais). No segundo experimento realizado após 11 meses, foram adicionadas as concentrações de 5 e $10 \mathrm{mM}$ de putrescina. Foi utilizado o delineamento inteiramente casualizado, disposto em esquema fatorial $2 \times 4 \times 2$ (agentes salinos $\times$ potenciais osmóticos $x$ concentrações de putrescina). As sementes foram avaliadas quanto a porcentagem de germinação e índice de velocidade de germinação (IVG). Menor porcentagem de germinação e IVG foram observadas à medida que os potenciais se tornam mais negativos quando as sementes foram submetidas ao estresse salino com $\mathrm{CaCl}_{2}$. A aplicação de putrescina promoveu aumento na porcentagem de germinação e IVG sob os potenciais mais negativos, com maiores valores na concentração de $5 \mathrm{mM}$.
\end{abstract}

Palavras-chave: Sucupira amarela, germinação, potencial osmótico, putrescina, regulador vegetal

ABSTRACT: Enterolobium schomburgkii (Benth.) Benth. seed germination under saline stress and polyamine application. The aim of this work was to evaluate the effects of salt stress by using $\mathrm{NaCl}$ and $\mathrm{CaCl}_{2}$ at the following osmotic potentials: 0 (control), $-0.2,-0.3$, and -0.4 $\mathrm{MPa}$ with and without putrescine application at $5 \mathrm{mM}$ and $10 \mathrm{mM}$. E. Schomburgkii seeds were previously scarified with sandpaper in the region opposite to the radicle, treated with fungicides and allowed to germinate in the different treatments at $30^{\circ} \mathrm{C}$. The experimental design was completely randomized, in a $2 \times 4$ (osmotic potentials $\times$ saline agents) factorial arrangement, with four replicates of 25 seeds each. After 11 months, a second experiment was carried out, in which putrescine concentrations of 5 and $10 \mathrm{mM}$ were added and the experimental design was completely randomized, in a $2 \times 4 \times 2$ (osmotic potentials $\times$ saline agents $\times$ putrescine concentrations) factorial arrangement. Germination percentage and velocity index (GVI) were evaluated. Germination percentage and GVI increased with lower potentials in seeds subjected to salt stress with $\mathrm{CaCl}_{2}$. Putrescine application $(5 \mathrm{mM})$ increased germination percentage and GVI at the most negative potentials.

Key words: Sucupira amarela, germination, osmotic potential, putrescine, plant growth regulator

\section{INTRODUÇÃO}

A espécie Enterolobium schomburgkii (Benth.) Benth. pertence à família Fabaceae ocorrendo na região amazônica na mata pluvial de terra firme, e também do sul da Bahia até o Rio de Janeiro em Mata Atlântica, sendo conhecida como faveira, orelha de macaco ou sucupira amarela, uma essência florestal cuja madeira possui valor econômico, usada em construções e marcenaria (Lorenzi, 2002), e cuja as folhas são indicadas para o tratamento de tumores cancerígenos (Esposito-Avella et al., 1985).

Recebido para publicação em 08/01/2008

Aceito para publicação em 31/10/2008

Rev. Bras. PI. Med., Botucatu, v.11, n.1, p.63-70, 2009. 
O período de germinação e estabelecimento das plântulas arbóreas é importante para a sobrevivência das espécies florestais, principalmente nos locais onde a disponibilidade de água está limitada durante um período do ano. A capacidade das sementes de algumas espécies germinarem sob condições de estresse hídrico confere vantagens ecológicas em relação a outras que são sensíveis à seca.

O processo germinativo se inicia com a absorção de água por embebição, porém, há necessidade de que a semente alcance um nível adequado de hidratação o qual permita a reativação dos seus processos metabólicos.

A velocidade dessa absorção varia para cada espécie, sendo condicionada, entre outros fatores, pela disponibilidade de água, que pode variar desde a saturação até próximo de zero, e pela pressão hidrostática. A disponibilidade e a velocidade do fluxo de água para a semente são determinadas pela diferença de potencial hídrico entre a semente e o solo (Bittencourt, 2004).

Em solos de regiões tropicais, a água subterrânea é a principal fonte de suprimento hídrico para as espécies florestais e está sujeita a salinização freqüente, causada pela alta força evaporativa do ar, que leva à saída de água da superfície do solo, tornando-a mais salinizada do que as camadas mais profundas. Sais contendo sódio, cálcio e magnésio, são os mais comuns e os elevados níveis de salinização afetam o potencial hídrico do solo, $\mathrm{pH}$ e a atividade microbiana. Em geral as sementes estão em ambiente mais salinizado do que as plântulas já estabelecidas, cujas raízes podem usar a porção menos salinizada do perfil do solo (Agboola, 1998).

O potencial hídrico é a diferença entre o potencial químico da água em um sistema, ou parte do sistema, e o potencial químico da água livre, em condições iguais de pressão atmosférica e temperatura. Este potencial é reduzido pela adição de substâncias polares e, ou, íons ao meio, já que as moléculas bipolares da água são atraídas e retidas por estes solutos, induzindo um decréscimo na atividade da água (Ferreira, 1988). Neste sentido, a indução da restrição hídrica é normalmente feita através da adição de solutos osmoticamente ativos. Entretanto, cada agente osmótico apresenta diferenças químicas que podem acarretar resultados diversos na germinação das sementes mesmo em potenciais hídricos similares (Sousa \& Cardoso, 2000).

Os sais, segundo Tobe et al. (2000), ocasionam inibição do crescimento tanto pelo efeito osmótico, ou seja, à seca fisiológica produzida, como pelo efeito tóxico, resultante da concentração de íons no protoplasma.
A concentração salina que causa o atraso e a redução no número de sementes germinadas depende da tolerância ao sal de cada espécie (Larcher, 2000).

Além do potencial osmótico, o controle do desenvolvimento das plantas está relacionado a grande quantidade de compostos orgânicos envolvidos (Colli, 2004). Dentre estes compostos encontram-se as poliaminas na qual se alteram quando as plantas são submetidas ao déficit hídrico.

As poliaminas são substâncias amplamente distribuídas por todas as células vegetais e exercem papel regulador sobre o seu crescimento e desenvolvimento, em concentrações micromolares. São essenciais para o crescimento vegetativo, particularmente para a divisão celular e morfologia (Galston \& Kauhr-Sawhney, 1994).

Segundo Matilla (1996), os conteúdos de poliaminas aumentam durante os estádios iniciais de germinação. Porém, ainda não está claro se as poliaminas estão envolvidas com a tolerância ao estresse osmótico ou se o aumento nos níveis desses compostos é um simples sintoma do estresse.

Estudos com poliaminas em sementes ainda são escassos, mas os resultados de alguns trabalhos, como os de Perez et al. (1999), Botelho \& Perez (2001) e Braga (2004), são promissores quando avaliaram o efeito de poliaminas sobre a atenuação do estresse promovido por diferentes agentes e potenciais osmóticos.

Tem sido mostrado, que em resposta a várias condições de estresse, como infecção por vírus, alta concentração de sais e deficiência de nutrientes, ocorre acúmulo de putrescina, enquanto a concentração de espermidina e espermina são menos influenciadas (Van Arendonk, 1998). Sobre a putrescina, Prakash et al. (1988) afirmaram que durante a germinação de sementes, a larga escala de hidrólise de macromoléculas no endosperma pode causar um desbalanço de $\mathrm{H}^{+}$intracelular e o concomitante acúmulo de putrescina pode ser um mecanismo compensatório para a manutenção do pH intracelular.

O presente trabalho teve como objetivo obter informações sobre o comportamento germinativo das sementes de Enterolobium schomburgkii, submetidas ao estresse salino, potenciais osmóticos e concentrações da poliamina putrescina.

\section{MATERIAL E MÉTODO}

O trabalho foi conduzido no Laboratório de Sementes da Universidade do Estado de Mato Grosso UNEMAT, Campus Alta Floresta - MT. As sementes de sucupira amarela [Enterolobium schomburgkii (Benth.) Benth. - Fabaceae) foram colhidas na cidade de Cláudia, MT em outubro de 2003.

Rev. Bras. PI. Med., Botucatu, v.11, n.1, p.63-70, 2009. 
Antes da montagem dos experimentos as sementes foram previamente escarificadas com lixa o 80 do lado oposto à radícula, e em seguida esterilizadas em hipoclorito de sódio a $20 \%$ por 30 minutos, sendo lavadas em água corrente por $10 \mathrm{~min}$, e em água destilada pelo mesmo período, quando então foram tratadas com os fungicidas Ridomil[ (Metalaxil) e Captan® (Orthocide 500) a 0,25\% em relação ao peso das sementes.

\section{Experimento I: Avaliação do estresse salino}

Para verificar o efeito do estresse salino, sobre a germinação das sementes, utilizaram-se soluções de $\mathrm{NaCl}$ e $\mathrm{CaCl}_{2}$ nos seguintes potenciais osmóticos: 0 (controle); -0,2; -0,3 e -0,4 MPa preparadas de acordo com a equação de Vant'Hoff, citada por Braga et al. (1999).

As sementes foram colocadas para germinar em caixas plásticas transparentes $(11 \times 11 \times 3 \mathrm{~cm})$, sobre papel Germitest $\AA$ umedecido com $15 \mathrm{~mL}$ das soluções à temperatura de $30^{\circ} \mathrm{C}$, sendo utilizadas quatro repetições de 25 sementes, em cada tratamento.

Foi utilizado o delineamento inteiramente casualizado, disposto em esquema fatorial $2 \times 4$ (agentes salinos $x$ potenciais osmóticos). Os dados foram submetidos à análise de variância e as médias comparadas pelo o teste de Tukey a $5 \%$ de probabilidade, sendo a porcentagem de germinação transformada em $\sqrt{+}$.

\section{Experimento II: Avaliação do estresse salino com a adição de concentrações de putrescina \\ Foram utilizados os mesmos agentes salinos e potenciais osmóticos descritos no experimento I, sendo adicionado às diferentes soluções, 5 e 10 mM}

de putrescina, e os volumes calculados para quatro repetições de 25 sementes, em cada tratamento.

Foram utilizadas nesse experimento sementes armazenadas por 11 meses em vidro lacrado e mantido à temperatura de geladeira (aproximadamente $10^{\circ} \mathrm{C}$ ). Após o armazenamento as sementes foram postas a germinarem em caixas plásticas transparentes $(11 \times 11 \times 3 \mathrm{~cm})$, sobre papel Germitest $\AA^{\circledR}$ umedecido com $15 \mathrm{~mL}$ das soluções +5 $\mathrm{mM}$ ou $10 \mathrm{mM}$ de putrescina, à temperatura $30^{\circ} \mathrm{C}$.

Foi utilizado o delineamento inteiramente casualizado, disposto em esquema fatorial $2 \times 4 \times 2$ (agentes salinos $x$ potenciais osmóticos $x$ concentrações de putrescina). Os dados foram submetidos à análise de variância e as médias comparadas pelo o teste de Tukey a $5 \%$ de probabilidade, sendo a porcentagem de germinação transformada em .

As avaliações de porcentagem e índice de velocidade de germinação (IVG) nos dois experimentos foram realizadas diariamente, sendo consideradas germinadas as sementes com aproximadamente $2 \mathrm{~mm}$ de raiz (Rehman et al., 1996). O experimento foi encerrado aos 11 dias. Os cálculos de IVG foram realizados de acordo com Maguire (1962).

\section{RESULTADO E DISCUSSÃO}

Experimento I: Avaliação do estresse salino

$\mathrm{Na}$ Tabela 1, observa-se os valores de $\mathrm{F}$, média geral, coeficiente de variação (\%) e diferença mínima significativa para a porcentagem de germinação e IVG.

Observa-se que ocorreu redução significativa

TABELA 1. Valores de F, média geral, coeficiente de variação (\%) e diferença mínima significativa (DMS) para germinação (\%) e Índice de velocidade de germinação (IVG) de sementes de Enterolobium schomburgkii em função de potenciais e agentes salinos.

\begin{tabular}{lrr}
\hline \multicolumn{1}{c}{ Causas de variação } & $\begin{array}{c}\text { Germinação } \\
(\%)\end{array}$ & IVG \\
\hline Agentes salinos & $51,62 *$ & $5,54 *$ \\
Potenciais & $72,57 *$ & $32,95 *$ \\
Agentes x potenciais & $12,01 \cdots$ & 0,85 NS \\
\hline Média geral & 5,59 & 4,29 \\
Coef. de variação & 15,68 & 48,93 \\
DMS Agentes salinos & 0,6395 & 1,5312 \\
DMS Potenciais & 1,2080 & 2,8923 \\
DMS Agentes (Potenciais) & 1,2791 & \\
DMS Potenciais (Agentes) & 1,7084 & \\
\hline
\end{tabular}

** Indica significativo a $5 \%$, pelo teste $\mathrm{F}$ * Indica significativo a $1 \%$, pelo teste $\mathrm{F}$ NS, não significativo 
TABELA 2. Valores médios de porcentagem de germinação de sementes de Enterolobium schomburgkii, submetidas a diferentes agentes e potenciais osmóticos.

\begin{tabular}{|c|c|c|}
\hline \multirow[t]{2}{*}{ Potenciais (MPa) } & \multicolumn{2}{|c|}{ Agentes salinos } \\
\hline & $\mathrm{NaCl}$ & $\mathrm{CaCl}_{2}$ \\
\hline 0 (controle) & $81,00 \quad \mathrm{Aa}$ & $81,00 \quad \mathrm{Aa}$ \\
\hline$-0,2$ & $44,00 \mathrm{Ba}$ & $36,00 \mathrm{Ba}$ \\
\hline$-0,3$ & $36,00 \mathrm{Ba}$ & $4,00 \mathrm{Cb}$ \\
\hline$-0,4$ & $26,00 \mathrm{Ba}$ & $1,00 \mathrm{Cb}$ \\
\hline
\end{tabular}

Médias seguidas pela mesma letra maiúscula na coluna e minúscula na linha não diferem entre si pelo teste de Tukey a $5 \%$ de probabilidade.

da porcentagem de germinação a partir do potencial à $-0,2 \mathrm{MPa}$ nos dois agentes salinos, sendo que no $\mathrm{CaCl}_{2}$ as reduções são mais acentuadas, quando comparadas com o $\mathrm{NaCl}$, e diferem estatisticamente, demonstrando que o estresse salino promovido pelo sal $\mathrm{CaCl}_{2}$ afeta mais a germinação desta espécie (Tabela 2).

Estes resultados foram semelhantes àqueles obtidos por Jeller \& Perez (1997) e Dickman et al. (2005), que relataram que o sal $\mathrm{CaCl}_{2}$ apresentou um efeito inibitório mais acentuado que o $\mathrm{NaCl}$ na germinação de sementes de Copaifera langsdorffi Desf. e Helianthus annuus L., respectivamente. Vieira (2005) também descreveu este comportamento para sementes de Parkia pendula (Willd.) Benth. ex Walp. que tiveram a germinação reduzida a partir de $-0,2$ $\mathrm{MPa}$ em solução de $\mathrm{CaCl}_{2}$ e a partir de $-0,3 \mathrm{MPa}$ em $\mathrm{NaCl}$, o mesmo verificado por Jacinto (2007) para sementes de Acacia mangium Willd., as quais tiveram redução significativa na porcentagem de germinação à partir de $-0,3 \mathrm{MPa}$ em soluções de $\mathrm{NaCl}$ e $-0,1$ $\mathrm{MPa}$ em soluções de $\mathrm{CaCl}_{2}$.

Entretanto, Fanti \& Perez (1998), em sementes de Adenanthera pavonina L., verificaram decréscimo menos acentuado na porcentagem de germinação com soluções de $\mathrm{CaCl}_{2}$ do que em soluções de $\mathrm{NaCl}$ nos mesmos potenciais. O mesmo comportamento foi verificado por Perez \& Tambeline (1995) para sementes de Prosopis juliflora (Sw.) DC. e por Fazolo (2006) em sementes de Stryphnodrendron barbatiman Mart.

Fanti \& Perez (2004) relataram que não observaram decréscimos na porcentagem de germinação de sementes de paineira (Chorisia speciosa St. Hil.) em presença dos sais $\mathrm{NaCl}$ e $\mathrm{CaCl}_{2}$, até o potencial osmótico de -0,4 $\mathrm{MPa}$, porém a partir de -0,6 MPa, reduções significativas na viabilidade foram registradas nos dois agentes osmóticos.
Santos et al. (1992) relataram que a salinidade afeta a germinação, não só dificultando a cinética de absorção da água, mas também facilitando a entrada de íons em quantidade tóxica nas sementes em embebição. O excesso de sais solúveis provoca uma redução do potencial hídrico do solo, induzindo menor capacidade de absorção de água pelas sementes e atuando como agente tóxico para o embrião, influindo na germinação, sendo que o alto teor de sais do solo, especialmente $\mathrm{NaCl}$, pode inibir a germinação, por causa dos efeitos osmóticos e tóxicos (Zekri, 1993).

De acordo com os dados de porcentagem de germinação encontrados para E. schomburgkii quando em soluções de diferentes potenciais osmóticos de $\mathrm{NaCl}$ e $\mathrm{CaCl}_{2}$ (Tabela 2), esta espécie deve estar incluída entre as glicófitas pouco tolerantes aos sais, pois não tolerou limite elevado de saturação, já que a germinação chegou a 26\% a -0,4 MPa. Por outro lado, sementes de Prosopis juliflora (Sw.) DC. (Perez, 1988) apresentaram um limite de tolerância ao sal em torno de -2,6 MPa para o $\mathrm{NaCl}$.

Deve-se considerar que os sais, segundo Prisco et al. (1981), inibem a mobilização de reservas, podendo, seus efeitos afetarem a síntese "de novo" e atividade das enzimas responsáveis pela hidrólise e translocação dos produtos hidrolizados dos tecidos de reserva para o eixo embrionário, afetando deste modo o processo germinativo. Além do efeito osmótico e tóxico, Larcher (2000) afirmou que a tolerância à salinidade envolve o grau de tolerância do protoplasma a um distúrbio no balanço iônico associado ao estresse salino ao qual depende da espécie vegetal, do tecido e do vigor.

Os valores de índice de velocidade de germinação (IVG) encontram-se na Figuras 1A e 1B. Reduções mais acentuadas no IVG foram observadas à medida que os potenciais tornaram-se mais negativos (Figura 1B), não havendo diferença significativa nos potenciais à $-0,2 ;-0,3$ e $-0,4 \mathrm{MPa}$.

A velocidade de germinação de sementes de Leucaena leucocephala (Lam.) de Wit., de acordo com Cavalcante \& Perez (1995), também sofreu redução na velocidade de germinação com o aumento do potencial. Resultados semelhantes foram observados por Fanti \& Perez (1996) em sementes de Bauhinia forficata Link., Botelho \& Perez (2001) em Peltophorum dubium (Spreng.) Taubert., Dickman et al. (2005) em Helianthus annuus L., Lima et al. (2005) em Oryza sativa L. e por Stefanello et al. (2006) em Foeniculum vulgare Miller.

A velocidade de germinação quando se utilizaram soluções de $\mathrm{CaCl}_{2}$, foi menor do que quando se utilizou $\mathrm{NaCl}$ (Figura 1A). O estresse hídrico pode reduzir tanto a porcentagem quanto a velocidade de germinação, com uma grande variação de respostas entre as espécies desde aquelas muito sensíveis até 

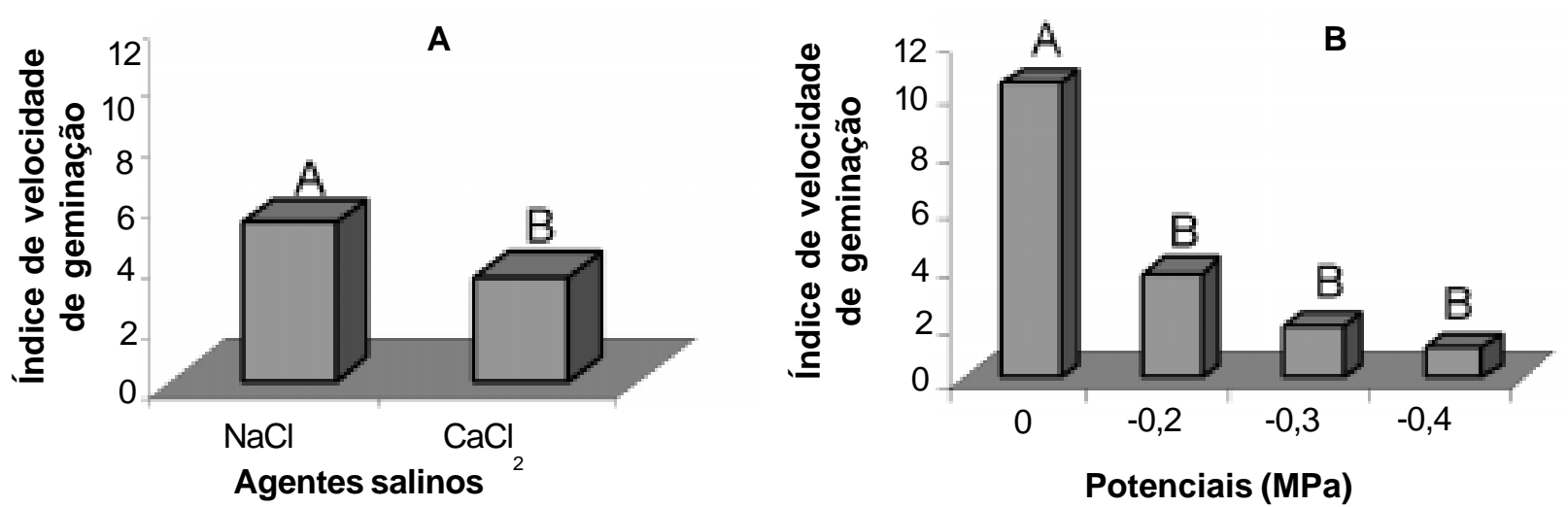

FIGURA 1. Índice de velocidade de germinação de sementes de Enterolobium schomburgkii submetidas a estresse salino com $\mathrm{NaCl}$ e $\mathrm{CaCl}_{2}(\mathrm{~A})$ e a diferentes potenciais osmóticos (B).

as mais resistentes (Bewley \& Black, 1994). Este comportamento pode ser explicado porque, quando há restrições na disponibilidade hídrica, a absorção de água pela semente se torna lenta. A semente inicia a germinação e, não havendo água suficiente para a sua continuidade, pode haver o impedimento da emissão da raiz primária (Lopes et al., 1996) ou até a morte do embrião.

Larcher (2000) afirmou que a água é osmoticamente retida pela solução salina e se a quantidade de sais excederem o nível da planta começa ocorrer distúrbios funcionais pelo efeito do sal no protoplasma. Esta afirmação poderia explicar o efeito mais negativo do $\mathrm{CaCl}_{2}$ sobre a velocidade do processo germinativo.

Os íons $\mathrm{Ca}^{2+}$ são essenciais na manutenção da integridade da membrana plasmática e contribuem para a diminuição do extravasamento de $\mathrm{K}^{+}$, o qual é responsável pela síntese de proteínas, amido e ativação de muitas enzimas no processo germinativo (Franco et al., 1999).

As ações de elementos tóxicos chegam a causar distúrbios fisiológicos na planta, sendo que a capacidade dos vegetais superiores de se adaptarem satisfatoriamente a salinidade depende da constituição fisiológica da planta e o seu estágio de crescimento (Nobrega Neto, 1999).

\section{Experimento II. Avaliação do estresse salino com adição de concentrações de putrescina \\ Observa-se que para todos os fatores} ocorreram diferenças significativas, com exceção dos agentes salinos na porcentagem de germinação (Tabela 3). Somente a interação entre potenciais e concentrações de putrescina foi significativa.

$\mathrm{Na}$ Tabela 4 verifica-se que houve uma oscilação, ora aumentando ou reduzindo os valores de porcentagem de germinação à medida que os potenciais tornaram-se mais negativos, sendo que na concentração de $5 \mathrm{mM}$ de putrescina os valores foram sempre superiores quando comparados a 10
$\mathrm{mM}$, indicando que a aplicação exógena deste regulador deve ser em menores concentrações. Comportamento também descrito por Botelho \& Perez (2001) para sementes de Peltophorum dubium (Spreng.) Taubert.

Os valores de porcentagem de germinação quando se utilizou putrescina (Tabela 4) diferem bastante de quando não se aplicou putrescina exógena (Tabela 2). À $0 \mathrm{MPa}$ (controle) houve redução da porcentagem de germinação das sementes, devido provavelmente, ao armazenamento das sementes de Enterolobium schomburgkii.

TABELA 3. Valores de F, média geral, coeficiente de variação (\%) e diferença mínima significativa (DMS) para germinação (\%) e Índice de velocidade de germinação (IVG) de sementes de Enterolobium schomburgkii em função de potenciais, agentes salinos e concentração de putrescina.

\begin{tabular}{|c|c|c|c|c|}
\hline Causas de variação & $\begin{array}{r}\text { Germina } \\
(\%)\end{array}$ & ใุ̣̂a & IVE & \\
\hline Agentes salinos & 0,99 & NS & 25,14 & *. \\
\hline Potenciais & 32,14 & $*$ & 42,01 & $*$ \\
\hline Concentraçōes & 23,30 & 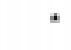 & 48,26 & $*$ \\
\hline Agentes X Potenciais & 0,69 & NS & 1,55 & NS \\
\hline Potenciais X Concentraçōes & 3,36 & + & 5,57 & $*$ \\
\hline Média geral & 6,08 & & 4,91 & \\
\hline Coef. de variaçăo & 14,91 & & 40,07 & \\
\hline DMS Agentes & 0,4555 & & 0,989 & \\
\hline DMS Potenciais & 0,8524 & & 1,851 & \\
\hline DMS Concentraçðes & 0,4555 & & 0,989 & \\
\hline DMS Potenciais (Conc.) & 1,2065 & & 2,618 & \\
\hline DMS Concentrações (Pot.) & 0,9109 & & 1,978 & \\
\hline
\end{tabular}


Quando se comparam os potenciais a - 0,3 e $-0,4 \mathrm{MPa}$, verifica-se que os valores nas concentrações de 5 e $10 \mathrm{mM}$ de putrescina (Tabela 4) são superiores aos observados sem a utilização de poliamina (Tabela 2), indicando que sob potenciais osmóticos mais reduzido s a aplicação de putrescina pode ter contribuído, conferindo maior resistência às sementes ao estresse salino. Estes resultados se assemelham aos obtidos por Botelho \& Perez (2001), para sementes de Peltophorum dubium (Spreng.) Taubert quando também verificaram aumento na porcentagem de germinação nos menores potenciais osmóticos (0,6; -0,8 e -1,0 MPa) após a aplicação de putrescina à 5 e $10 \mathrm{mM}$.

Fonseca (1999) aplicou poliaminas em sementes de Adenanthera pavonina L., e não observou durante o processo germinativo ampliação dos limites de tolerância aos sais $\mathrm{NaCl}$ e $\mathrm{CaCl}_{2}$, nem atenuação do estresse entre os potenciais 0 (controle) e $-1,4$ $\mathrm{MPa}$.

Villanueva \& Huang (1993) relataram que, durante o período de quebra de dormência tardio e no inicio do processo de embebição, as concentrações de poliaminas aumentam e ficam semelhantes às de RNA, DNA e proteínas, sugerindo que as poliaminas sejam essenciais ao processo germinativo. Smith (1985) afirmou que as poliaminas interagem com grupos aniônicos em membranas, prevenindo o extravasamento celular e promovendo estabilização em condições de estresse. As funções fisiológicas das poliaminas, embora não estejam devidamente esclarecidas, sua ocorrência em altas concentrações nos tecidos em crescimento rápido, sugere a participação na proliferação e desenvolvimento das células.

Para Street \& Opik (1983) o déficit hídrico altera a permeabilidade da membrana e as

TABELA 4. Valores médios da porcentagem de germinação de sementes de Enterolobium schomburgkii submetidas a potenciais osmóticos e a concentrações de putrescina.

\begin{tabular}{cccc}
\hline \multirow{2}{*}{ Potenciais (MPa) } & \multicolumn{3}{c}{ Poliamina Putrescina } \\
\cline { 2 - 4 } & $54 \mathrm{mM}$ & \multicolumn{2}{c}{$10 \mathrm{mM}$} \\
\hline 0 (controle) & $54,76 \mathrm{Aa}$ & $50,48 \mathrm{Aa}$ \\
$-0,2$ & $33,45 \mathrm{Ba}$ & $22,54 \mathrm{Bb}$ \\
$-0,3$ & $54,76 \mathrm{Aa}$ & $43,49 \mathrm{Aa}$ \\
$-0,4$ & $33,07 \mathrm{Ba}$ & $12,06 \mathrm{Cb}$ \\
\hline
\end{tabular}

Médias seguidas pela mesma letra maiúscula na coluna e minúscula na linha não diferem entre si pelo teste de Tukey a $5 \%$ de probabilidade. propriedades do tonoplasto, permitindo a interação entre proteínas citoplasmáticas e enzimas hidrolíticas. De acordo com o pH do meio celular, as poliaminas podem afetar a síntese e a atividade de macromoléculas, a permeabilidade da membrana e processos parciais de mitose e meiose. As poliaminas podem neutralizar as mudanças induzidas por hormônios na permeabilidade da membrana celular, um dos prováveis alvos da poliamina (Galston \& Kauhr-Sawhney, 1994).

Na Tabela 5 pode-se observar oscilações nos valores de índice de velocidade de germinação com a redução dos potenciais, com maiores índices na concentração de $5 \mathrm{mM}$ de putrescina. Nos potenciais à $-0,3$ e $-0,4 \mathrm{MPa}$, os valores são maiores quando comparados com o IVG sem a aplicação de putrescina (Figura 1B). Fonseca (1999) também verificou aumento na velocidade de germinação de sementes de Adenanthera pavonina L. nos potenciais entre $-0,8$ e $-1,4 \mathrm{MPa}$ de $\mathrm{NaCl}$, após a aplicação de putrescina. Botelho \& Perez (2001) relataram que a adição de putrescina $5 \mathrm{mM}$ provocou aumento nos valores de porcentagem e velocidade de germinação de sementes de Peltophorum dubium (Spreng.) Taubert.

TABELA 5. Índice de velocidade de germinação (IVG) das sementes de Enterolobium schomburgkii submetidas a potenciais osmóticos e a concentrações de putrescina.

\begin{tabular}{crc}
\hline & \multicolumn{1}{c}{ Poliamina } & Putrescina \\
\cline { 2 - 3 } Potenciais (MPa) & \multicolumn{1}{c}{$5 \mathrm{mM}$} & $10 \mathrm{mM}$ \\
\hline 0 (controle) & $10,12 \mathrm{Aa}$ & $6,74 \mathrm{Ab}$ \\
$-0,2$ & $3,00 \mathrm{Ba}$ & $1,80 \mathrm{Ba}$ \\
$-0,3$ & $10,12 \mathrm{Aa}$ & $3,43 \mathrm{Bb}$ \\
$-0,4$ & $3,22 \mathrm{Ba}$ & $0,83 \mathrm{Bb}$ \\
\hline
\end{tabular}

Médias seguidas pela mesma letra maiúscula na coluna e minúscula na linha não diferem entre si pelo teste de Tukey a $5 \%$ de probabilidade.

Pode-se verificar na Figura 2, que houve efeito isolado dos agentes salinos ocorrendo maior IVG quando as sementes foram submetidas ao $\mathrm{NaCl}$, sendo os valores superiores aos obtidos quando não se aplicou putrescina às soluções salinas (Figura $1 \mathrm{~A}$ ). Este resultado se assemelha ao obtido por Fonseca (1999) em Adenanthera pavonina $\mathrm{L}$. que verificou maior velocidade de germinação com aplicação de $\mathrm{CaCl}_{2}+$ putrescina $\left(100 \mathrm{mg} \mathrm{L}^{-1}\right)$.

Independente da concentração da poliamina os valores de porcentagem de germinação e IVG foram

Rev. Bras. PI. Med., Botucatu, v.11, n.1, p.63-70, 2009. 
mais elevados na presença da poliamina putrescina. Este estudo permitiu verificar que as poliaminas possuem ação na atenuação do estresse salino em sementes de Enterolobium schomburgkii. Esta atenuação é indicada pelo aumento significativo na germinabilidade e velocidade de germinação provavelmente porque, as poliaminas atuam nas membranas, prevenindo o extravasamento, causando uma estabilização em condições de estresse (Galston \& Kauhr-Sawhney, 1994).

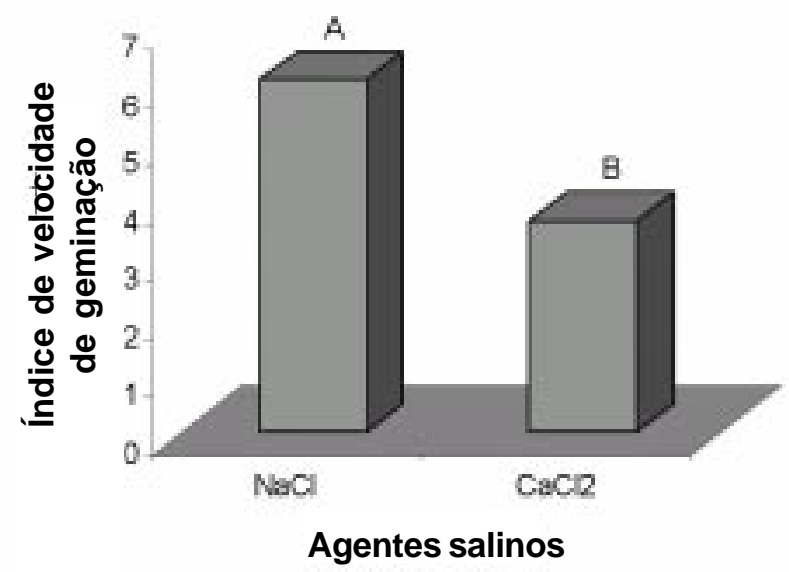

FIGURA 2. Índice de velocidade de germinação de sementes de Enterolobium schomburgkii, submetidas aos agentes salinos $\mathrm{NaCl}$ e $\mathrm{CaCl}_{2}$ e à poliaminas putrescina.

Galston \& Kauhr-Sawhney (1994) afirmaram que as poliaminas são responsáveis por muitos controles fisiológicos, dentre eles o estresse, e aplicações externas podem afetar importantes processos fisiológicos.

Hebling (1997) também verificou que as poliaminas foram efetivas em atenuar o estresse hídrico, levando se em consideração a porcentagem e velocidade. Assim, é provável que a poliamina putrescina tenha ação mais diretamente atenuando os efeitos deletérios do estresse, alterando a permeabilidade da membrana e participando dos processos de crescimento do embrião.

\section{CONCLUSÃO}

A germinação e o IVG das sementes de Enterolobium schomburgkii foram afetadas pelo estresse salino causado pelo $\mathrm{CaCl}_{2}$, à medida que os potenciais osmóticos se tornaram mais negativos.

A aplicação da poliamina putrescina promoveu aumento na porcentagem de germinação e IVG sob os potenciais mais negativos, com maiores valores na concentração de $5 \mathrm{mM}$.

\section{AGRADECIMENTO}

Os autores agradecem ao FIDPEX e ao PIBIC/UNEMAT, pelo apoio financeiro e a bolsa de iniciação científica da terceira autora.

\section{REFERÊNCIA}

AGBOOLA, D.A. Effect of saline solutions and salt stress on seed germination of one tropical forest tree species. Revista de Biologia Tropical, v.46, n.4, p.1109-15, 1998. BEWLEY, J.D.; BLACK, M. Seeds: physiology of development and germination. 2.ed. New York: Plenum Press, 1994. 445p.

BITTENCOURT, M.L.C. et al. Efeito do condicionamento osmótico das sementes na germinação e no crescimento das plântulas de aspargo. Revista Brasileira de Sementes, v.26, n.1, p.50-6, 2004.

BOTELHO, B.A.; PEREZ, S.C.J.G.A. Estresse hídrico e reguladores de crescimento na germinação de sementes de canafístula. Scientia Agrícola, v.58, n.1, p.43-9, 2001.

BRAGA, L.F. et al. Efeito da disponibilidade hídrica do substrato na qualidade fisiológica de sementes de feijão. Revista Brasileira de Sementes, v.21, n.2, p.95102, 1999.

BRAGA, L.F. Poliaminas em sementes de Erythrina mulungu Mart. (Fabaceae) submetidas a diferentes potenciais osmóticos. 2004. 95p. Tese (Doutorado Área de concentração em Botânica) - Instituto de Biociências, Universidade do Estado de São Paulo, Botucatu.

CAVALCANTE, A.M.B.; PEREZ, S.C.J.G.A. Efeito dos estresses hídrico e salino sobre germinação de sementes de leucena. Pesquisa Agropecuária Brasileira, v.30, n.2, p 281-9, 1995.

COLLI, S. Outros reguladores: Brassenosteróides, Poliaminas, Ácidos jasmônico e salicílico. In: KERBAUY, G.B.; GUERA, M.P. Fisiologia vegetal. Rio de Janeiro: Guanabara Koogan, 2004. p.333-40.

DICKMAN, L. et al. Comportamento de sementes de girassol (Helianthus annuus L.) submetidas a estresse salino. Revista de Ciências Agro-Ambientais, v.3, p.6575, 2005.

ESPOSITO-AVELLA, M. et al. Pharmacological screening of Panamanian medicinal plant. Part I. International Journal of Crude Drug Research, v.23, n.1, p.17-25, 1985.

FANTI, S.C.; PEREZ, S.C.J.G.A. Efeitos do estresse hídrico e salino na germinação de Bauhinia forficata Link. Ceres, v.43, n.249, p.654-62, 1996.

FANTI, S.C.; PEREZ, S.C.J.G.A. Efeitos do estresse hídrico, salino e térmico no processo germinativo de sementes de Adenanthera pavovina L. Revista Brasileira de Sementes, v.20, n.1, p.167-77, 1998.

FANTI, S.C.; PEREZ, S.C.J.G.A. Processo germinativo de sementes de paineira sob estresses hídrico e salino. Pesquisa Agropecuária Brasileira, v.39, n.9, p.903-9, 2004.

FAZOLO, C. Superação da dormência de sementes de Stryphnodendron barbatiman Mart. e avaliação da germinação sob estresse osmótico. 2006. 23p. 
Monografia (Conclusão de curso de Agronomia) Universidade do Estado de Mato Grosso, Alta Floresta. FERREIRA, L.G.R. Fisiologia vegetal: relações hídricas. Fortaleza: Edições Universidade Federal do Ceará, 1988. 137p.

FONSECA, S.C.L. Efeitos de poliaminas, polietileno glicol, sais e temperatura na germinação de sementes Adenanthera pavonina L. (Fabaceae). 1999. 116p. Dissertação (Mestrado - Área de concentração em Ecologia e Recursos Naturais) - Universidade Federal de São Carlos, São Carlos.

FRANCO, O.L. et al. Effects of $\mathrm{CaCl}_{2}$ on the growth and osmoregulator accumulation in $\mathrm{NaCl}$ stressed cowpea seedlings. Revista Brasileira de Fisiologia Vegetal, v.11, p.145-51, 1999.

GALSTON, A.W.; KAUR-SAWHNEY, R. Polyamines as endogenous growth regulators. In: DAVIES, P.J. Plant hormones: their role in plant growth and development. 2.ed. New York: Nijhoff Publishers, 1994. p.280-95.

HEBLING, S.A. Aspectos ecofisiológicos da germinação de sementes de Enterolobium contortisiliquum (Vellozo) Morong. 1997. 143p. Tese (Doutorado - Área de concentração em Ecologia e Recursos Naturais) Centro de Ciências Biológicas e da Saúde. Universidade Federal de São Carlos, São Carlos.

JACINTO, J.D. Superação da dormência, influência da temperatura, luz e estresse osmótico sobre a germinação de sementes de Acacia mangium Willd. 2007. 30p. Monografia (Conclusão de curso de Engenharia Florestal) - Universidade do Estado de Mato Grosso, Alta Floresta.

JELLER, H.; PEREZ, S.C.J.G.A. Efeito da salinidade e da semeadura em diferentes profundidades na viabilidade e no vigor de Copaifera langsdorffi Desf. Caesalpiniaceae. Revista Brasileira de Semente, v.19, n.1, p. 219-25, 1997.

LARCHER, W. Ecofisiologia vegetal. São Carlos: RiMa, 2000. 531p.

LIMA, M.G.S. et al. Qualidade fisiológica de sementes de arroz submetidas a estresse salino. Revista Brasileira de Sementes, v.27, n.1, p.54-61, 2005.

LOPES, H.M. et al. Influência do potencial osmótico e da temperatura na embebição e no crescimento da radícula de sementes de cebola (Allium cepa L.). Revista Brasileira de Sementes, v.18, n.2, p.167-72, 1996.

LORENZI, H. Árvores brasileiras: manual de identificação e cultivo de plantas arbóreas nativas do Brasil. v.1. Nova Odessa: Instituto Plantarum, 2002. 368p. MAGUIRE, J.D. Speed of germination and in selection and evaluation for seedling emergence and vigour. Crop Science, v.2, n.1, p.176-77, 1962.

MATILLA, A.J. Polyamines and seed germination. Seed Science Research, v.6, p.81-93, 1996.

NOBREGA NETO, G.M. et al. Efeito da salinidade na germinação e desenvolvimento inicial de leucena. Revista Brasileira de Engenharia Agrícola e Ambiental, v.3, n.2, p.257-60, 1999.

PEREZ, S.C.J.G.A. Aspectos ecofisiológicos da germinação de sementes de Prosopis juliflora (Sw.) DC. 1988. 214p. Tese (Doutorado em Ciências Biológicas)
Universidade Federal de São Paulo, São Carlos. PEREZ, S.C.J.G.A. et al. Eficiência de reguladores de crescimento na atenuação do estresse salino em sementes de canafístula (Peltophorum dubium (Spreng) Taub). Revista de Tecnologia do Ambiente, v.5, n.2, p.6376, 1999.

PEREZ, S.C.J.G.A.; TAMBELINI, M. Efeito do estresse salino e hídrico e do envelhecimento precoce na germinação de algarobeira (Prosopis juliflora). Pesquisa Agropecuária Brasileira, v.30, p.1289-95, 1995.

PRAKASH, L.; DUTT, M.; PRATHAPASENAN, G. NaCl alters contents of nucleic acids, protein, polyamines and the activity of agmatine deiminase during germination and seedling growth of rice (Oryza sativa L.). Australian Journal of Plant Physiology, v.15, n.6, p.769-76, 1988. PRISCO, J.T. et al. Effect of $\mathrm{NaCl}$ salinity on cotyledon starch mobilization during germination of Vigna unguiculata (L.) Walp. seeds. Revista Brasileira de Botânica, v.4, n.2, p.63-71, 1981.

RAVEN, P.H. et al. Biologia vegetal. Rio de Janeiro: Guanabara Koogan, 2001. 659p.

REHMAN, S. et al. The effect of sodium chloride on germination and the potassium and calcium contents of Acacia seeds. Seed Science and Technology, v.25, n.1, p.45-57, 1996.

SANTOS, V.L.M. et al. Efeito do estresse salino e hídrico na germinação e vigor de sementes de soja. Revista Brasileira de Semente, v.14, n.2, p.1311-7. 1992.

SMITH, T.A. Polyamines. Annual Review of plant physiology, v.36, p.117-43, 1985.

SOUSA, G.M.; CARDOSO, V.J.M. Effects of different environmental stress on seed germination. Seed Science Technology, v.28, n.3, p.621-30, 2000.

STEFANELLO, R. et al. Efeito da luz, temperatura e estresse hídrico no potencial fisiológico de sementes de funcho. Revista Brasileira de Sementes, v.28, n.2, p.135-41, 2006.

STREET, H.E.; OPIK, H. The physiology of flowering plants, their growth and development. Maryland: Edward Arnolds, 1983. 279p.

TOBE, K. et al. Seed germination and radicle growth of a halophyte, Kalidium caspicum (Chenopodiaceae). Annals of Botany, v.85, n.3, p.391-6, 2000.

VANARENDONK, J.J.C.M.et al. Polyamine concentrations in four Poa species, differing in their maximum relative growth rate, growth with free access to nitrate and at limiting nitrate supply. Plant Growth Regulation, v.24, n.2, p.77-89, 1998.

VIEIRA, R. Efeito do estresse hídrico e salino na germinação de sementes de Parkia pendula (Willd.) Benth. 2005. 28p. Monografia (Conclusão de curso de Engenharia Florestal) - Universidade do Estado de Mato Grosso, Alta Floresta.

VILLANUEVA, V.R.; HUANG, H. Effect of polyamine inhibition on pea seed germination. Journal of Plant Physiology, v.141, p.336-40, 1993.

ZEKRI, M. Salinity and calcium effects on emergence, growth and mineral composition of seedlings of eight citrus rootstocks. Hortscience, v.68, n.11, 53-62, 1993.

Rev. Bras. PI. Med., Botucatu, v.11, n.1, p.63-70, 2009. 